Surely the essential feature is the presence of a significant degree of mitral stenosis -that is to say, enough to raise left atria pressure under various conditions such as exercise, emotion, pregnancy, or tachycardia from any cause. Operation for removal of clot is not an accepted procedure apart from valvotomy.

The statement that valvotomy is indicated "provided the valve is suitable for it" is in our experience mianingless because what the surgeon will be able to achieve cannot by any method be predicted preoperatively. The unreliability of the signs of a so-called pliant valve have been previously stressed.5 An excellent valvotomy may be achieved in a patient without the signs of a pliant valve, and it may be difficult to make a good valvotomy in a patient in whom the signs are clear.

It will be apparent that we do not believe the case has been made for a greater role of long-term anticoagulant treatment in mitral disease, but we do consider that multicentre controlled trials are long overdue. In Britain the difficulty increases each year with the decreasing number of patients who require a first valvotomy. The opportunity lies in such countries as India and Pakistan. If young patients in sinus rhythm are to be put on long-term anticoagulants not only will the task be formidable but there will be many complications. Apart from the difficulties inherent in laboratory techniques, drug interference with anticoagulant control is an increasing hazard. We do not at present believe that there is any evidence for permanent, long-term treatment of patients with anticoagulants after valvotomy.

In conclusion, we consider that possibly anticoagulants could, at a price, make a modest contribution to decreasing the incidence of systemic embolism, but as yet there is inadequate evidence because appropriate trials have not been carried out.

It must be remembered that oral anticoagulants have no effect on platelet aggregation, and in other situations at least little effect on the systemic side of the circulation in comparison with that on the venous side. Once again, multicentre controlled trials are long overdue.-We are, etc.,

RICHARD TURNER ANDREW LOGAN ARTHUR KITCHIN

University of Edinburgh

1 Smith, B., Umapathy, A., Bentall, H. H., and Cleland, W. P., British Heart fournal, 1965 , 2 Coulshed, N., Epstein, E. J., McKendrick, C. S., Galloway, R. W. and Walker, E., British Heart
fournal, 1970, 32, 26 .

Medical Fourmal, 1964, 2, 1167. R. J., British
Szekely, P., British Medical Ұournal, 1964, 1,

Turrer, R. W. D., British Medical fournal, 1968,
2, 383 .

Imipramine and Pregnancy

SIR,-The recent publicity (The Times, 4 March) given to the alleged relationship between the prescribing of imipramine to pregnant women and fetal abnormalities prompts me to put before your readers some facts which should help them to decide whether the drug should be prescribed to pregnant women.

I have been using imipramine as an antidepressant since 1959 after conducting a clinical trial. ${ }^{1}$ I soon realized it was an effective antidepressant and, being rather conservative in these matters, I have used it continuously and almost exclusively ever since. At the time Dr. McBride's report on the possible dangers of imipramine to the fetus was given such wide publicity I was preparing a report to the Lane Committee on the Abortion Act. While indexing my extensive material relating to mental instability and pregnancy the following facts emerged.

Since 1959, 211 of my patients have exhibited instability during their pregnancies, and of these 81 were given imipramine for depressive symptoms, the dose invariably being $50 \mathrm{mg}$ three times a day and the duration not less than two months. All these pregnancies were followed up with particular reference to the mother's mental health and the child's mental and physical development. In no instance did these children suffer from fetal abnormalities sufficiently material to be reported by the Maternity and Child Welfare Service, by the family doctor, or by the mother.

Among those patients who were treated since 1959 for instability following pregnancy there were nine patients who had an abnormal child. These included two with Down's syndrome, one with multiple deformities which died, one with spina bifida which also died, one with a congenital heart defect which died following a corrective operation, and four who were still-born. Not one of the mothers of these children had been given imipramine during pregnancy. The mother of the spina bifida baby had imipramine a year prior to her pregnancy and so had a mother with a still-born child.

These fairly substantial figures do not support the view that imipramine is liable to cause fetal abnormalities if given to pregnant women either early or late in their pregnancies; in fact, a number became pregnant while on the drug. I shall therefore continue to prescribe the drug to pregnant women and shall not withdraw it from a patient should she become pregnint. I do not see the issue even as a calculated risk for I have no evidence of such risk.-I am etc.

Queen Elizabeth Hospital,

MYRE SIM Birmingham

White, H. C., and Sim, M., Birmingham Medical

\section{Malformed Infant}

SIR,-I have recently examined at necropsy a grossly malformed infant born to a mother who had been taking Tofranil (imipramine) during the first four weeks of pregnancy. The patient was 28 and had had one previous miscarriage and one normal infant This latter pregnancy had been complicated by puerperal mania, which was treated with Tofranil. She was maintained on this drug for 15 months prior to her most recent conception and for four weeks subsequently. Her dose while pregnant was $10 \mathrm{mg}$ b.d. There was marked hydramnios at 32 weeks by dates, and shortly thereafter she delivered a female stillborn infant.

This infant had an exencephaly, cleft palate, adrenal hypoplasia, and a large rightsided diaphragmatic hernia. Postmortem radiography of the fetus demonstrated iniencephaly, cervical and upper thoracic dysraphia, and multiple rib defects. No abnormality of the limbs was observed. It is likely that the primary fault was a disturbance of neurulation in the cephalic half of the embryo and that the other anomalies were secondary to this. Neurulation is normally completed by the end of the fourth gestational week.

The significance of single observations of this type can only be assessed in the light of the accumulated evidence. In relation to the widespread use of the drug there are few such reports in the literature, and they are probably no more in number than that which might be anticipated to occur by chance. Statistical proof for mild degrees of teratogenicity of any drug is very dependent on the frequency with which possible instances are referred to central bodies such as the Committee on Safety of Drugs. It will be interesting to see how current interest in the possible teratogenic properties of imipramine will stimulate the collection of this information.-I am, etc.,

St. Mary's Hospital,

A. J. BARSON

Whitworth Park,

\section{Rapid Irregular Movements of} Eyes and Limbs

SIR,-The description by Drs. G. Pampiglione and Maria Maia of a syndrome of rapid irregular movements of eyes and limbs in childhood (R.I.M.E.L.) (19 February, p. 469) brings to light once more a group of motor disorders of unknown cause which frequently prove difficult to classify clinically. It is suggested that R.I.M.E.L. may b? a distinct entity, distinguishable from acute cerebellar ataxia of childhood on clinical grounds but more accurately by electrophysiological criteria.

I should like briefly to draw attention to an intriguing syndrome of involuntary movements which includes components of both cerebellar ataxia and R.I.M.E.L. This disease, originally known as encephalitis tremens, ${ }^{1}$ is virtually restricted to a single region of Western Nigeria around the town of Ilesha. It consists of a "flu-like" illness often associated with giddiness, which after a short prodromal phase is accompanied by gross, generalized ataxia. Desp'te the severity, ataxic symptoms are of short duration and often remit within a week. All age groups may be affected and a review of 109 cases $^{2}$ showed an age range from three months to 68 years. This is in distinction to the previously described and clinically similar syndrome of acute cerebellar ataxia of childhood.

I think two aspects of this disease justify further report. Firstly, the clinical features, which are of acute cerebellar ataxia-manifested by intention tremor, truncal ataxia and broad-based gait, but also accompanied by irregular shivering or shuddering movements of the limbs, trunk, and head. These occur during voluntary movement and equally during static extension of the arms and legs, and are abolished by resting or sleep. Irregular conjugate jerking of the eyes in the horizontal plane is seen in a number of cases and occurs independently of tremors.

Secondly, review of cases admitted between 1964 and $1967^{2}$ revealed a marked sea. sonal incidence with outbreaks occurring every September, October, and November. 
There are few reports of acute cerebellar ataxia presenting in adults and it is of interest that Brumlik and Means ${ }^{3}$ describe two American cases showing "lightening eye movements, peculiar shuddering tremor and cerebellar ataxia."

It is tempting to postulate that encephalitis tremens, a benign epidemic form of acute cerebellar ataxia with R.I.M.E.L. limited geographically to a region of West Africa rain forest, might represent an abor virus encephalitis involving the brainstem. However, such an assumption awaits investigation. -I am, etc.,

Royal West Sussex Hospital,

Hugh COAKHam

1 Wright, J., and Morley, D. C., Lancet, 1958, 1 2 Personal study while in receipt of Leverhulme 3 Brumlik, J., and Means, E. D., Brain, 1969, 92, 157.

\section{Oxytocin Release by Infused Prostaglandin}

SIR,-Dr. Arnold Gillespie and others, results on oxytocin release by infused prostaglandins (26 February, p. 543) are very interesting, but I feel that though the possibility cannot be excluded not enough evidence was provided to allow the conclusion that administered prostaglandins act directly on the pituitary to release oxytocin.

No peripheral oxytocin was detected in one patient in whom prostaglandins did not stimulate uterine activity. This could imply not only that direct prostaglandin-induced oxytocin release from the pituitary is required to enhance uterine activity when administering exogenous prostaglandins, but that prostaglandin-induced uterine contractions might indirectly stimulate the pituitary, even though this may be by release of further amounts of prostaglandin.

Amounts of oxytocin found in prostaglandin-induced labours were similar to those found in the late first stage of spontaneous labour, and seem to indicate little difference in pituitary involvement in these two situations. The observed oxytocin release in males and females could also arise indirectly from one of the many known pharmacological actions of prostaglandinsfor example, on renal and intestinal systems.

As further evidence for posterior-pituitary involvement in the action of prostaglandins they cite investigations ${ }^{12}$ showing that spontaneous and prostaglandin-induced contractions can be inhibited by ethanol whereas exogenous oxytocin-induced contraction are not. This assumes that spontaneous contractions are the direct result of endogenous oxytocin release, which may not be so. Indeed one might hypothesize from this evidence that it is endogenous prostaglandin release that is effecting uterine contraction in spontaneous labour. Mantell and Liggins ${ }^{3}$ have shown that ethanol can reduce exogenous oxytocin-induced contractions, and therefore the use of ethanol to define the role of prostaglandins and oxytocin in the control of uterine activity must be viewed with some caution.-I am, etc.,

KeIth Hillier Nuffield Department of Obstetrics and Gynaecology, Radcliffe Infirmary,

Oxford

1 Fuchs, F., Fuchs, A-R., Poblete, V. F., and Risk, cology, 1967, 99, 627 .
2 Karim, S. M. M., and Sharma, S. D., Fournal of Obstetrics and Gynaecology

Mantell, C. D., and Liggins, G. C., fournal of Obstetrics and Gynaecology of the British Com monwealth, 1970, 77, 976.
moltrics

\section{Genetic Counselling}

SIR,-The table quoted by Professor C. A. Clarke (4 March, p. 606) from Redding and Hirschhorn gives a threefold increased risk of a subsequent sib being affected by Down's syndrome throughout the maternal age range. This is in fact the order of the overall increased risk to a mother who has had one affected child irrespective of her age or the type of chromosome anomaly. ${ }^{1}$ But Carter and Evans ${ }^{2}$ showed that most of the increased risk is due to balanced translocation or other factors than maternal age, A mother of a child with trisomy 21 , proper, where both parents have a normal chromosome complement, has only a very slightly increased risk above the appropriate to her age. Thus a mother aged 35 years or more at the birth of her first affected child has approximately the same risk of having a second child with Down's syndrome as other members of her age group.-I am, etc.,

BRIAN H. KIRMAN

Oueen Mary's Hospital for Children,

Carshalton

1 Berg, J. M., and Kirkman, B. H., Archives of
Disease in Childhood, 1961, 36. 645.
2 Carter, C. O., and Evans, K. A., Lancet, 1961,
2, 785 .

\section{Irritable or Irritated Bowel}

SIR,-Your leader on the "Irritable Bowel Syndrome" (22 January, p. 197) is an excellent summary of the confusion that has grown up around this symptom complex, which is so ill-defined that one wonders if it really exists.

Everyone is agreed that the function of the intestine is disturbed, and that as yet no structural abnormality has been demonstrated to account for the very genuine symptoms attributed to an irritable bowel. As there is no evidence that the bowel is intrinsically abnormal, it is a pity that the title of this leader perpetuates the assumption that the intestine is primarily at fault. Perhaps the cause of these symptoms should be sought elsewhere.

There is a growing body of evidence which shows that our modern Western diet is abnormal and that this causes several diseases which have appeared on the clinical scene in this century. ${ }^{1-3}$ One of these diseases is diverticulosis of the colon, which has been said by some to be connected with the "irritable bowel syndrome." Certainly, both conditions are common in Western nations and almost unknown in rural Africans. ${ }^{4}$ It is also true that symptoms ranging from vague dyspepsia, heartburn, anorexia, nausea, distention, fullness, and flatulence to generalized abdominal aching and severe colic are common both to diverticulosis and to the irritable bowel syndrome. Furthermore, borh may be associated with bowel habits which may vary from constipation to episodes of diarrhoea or to the frequent passing of small hard stools.

In the case of diverticulosis, these symptoms are not caused by the diverticula because they can be relieved or abolished in
$85 \%$ of patients merely by replacing the cereal fibre that is lacking in our modern diet. This is done by adding unprocessed bran to the food and reducing the intake of refined sugar. ${ }^{56}$ Over the last five years, it has been my experience that a high fibre/ low sugar diet relieves or abolishes these very same symptoms in patients who do not have diverticula and in whom no abnormality of the intestine has been demonstrated. Consequently, I believe that these symptoms are often caused by an intestine that is struggling with our modern fibre-deficient diet.

None of the observations recorded in your leading article is inconsistent with the theory that these symptoms are caused by a normal bowel whose function is disturbed by its having to cope with an altered environment. This environment changed dramatically when the refining of carbohydrates became widespread only a century ago. The addition of fibre in the form of unprocessed bran in a quantity sufficient to render the stools soft and passed without straining will relieve these symptoms in most patients. The rural African passes soft bulky stools and does not suffer from diverticulosis or from an irritable bowel. In countries where the "irritable bowel syndrome" is common, the diet is so fibre-deficient that it causes the colon to rupture itself so that diverticula appear. If the bowel is being subjected to such an abnormal diet, is it fair to refer to the "irritable" bowel syndrome? Surely it would be wiser to refer to the "irritated" bowel syndrome.

The term irritable bowel syndrome implies that the design or construction of the intestine is intrinsically wrong and it cannot cope with the normal stresses of everyday life. Can this really be so in over half the patients who attend our clinics? It seems more likely that, owing to evolution and natural selection, their bowels are normal but their symptoms are caused by the food they eat. I am, etc., Manor House Hospital
London N.W.11

N. S. PAinter

Cleave, T. L., Campbell, G. D., and Painter N. S., Diabetes, Coronary Thrombosis and the
Saccharine Disease, 2nd edn. Bristol, J. Wright, Sacchar 1969 .

Painter, N. S., and Burkitt, D. P., Briti-h Medical

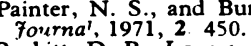

Burkitt. D. P.. Lancer, 1970, 2. 1237

Troweli, $\dot{H}$. C.., Non-infective Diseases in Africa, London.

Painter, N. S., British Medical fournal, 1971, 2. 156. Painter, N. S., Almeida, A. Z., and Colebourne,
K. W., British Medical fournal, 1972, in press.

\section{Vasodilating Action of L-dopa}

SIR,-The studies of Spiers and Calne ${ }^{1}$ and Spiers ${ }^{2}$ show that dona and dopamine have a noradrenaline-liberating action at the sympathetic nerve endings with depletion of stores. Both substances are also metabolic precursors of adrenaline and noradrenaline. In order to investigate a possible peripheral vasodilating action of $L$-dopa we have treated a group of 10 patients affected by an atherosclerotic obstructive arterial disease of the lower limbs for more than two years.

L-dopa was administered in increasing dosage from $375 \mathrm{mg} /$ day to a maximum of $3,000 \mathrm{mg} /$ day. All patients were treated for a month and no other drug was administered. Rheographic registrations ${ }^{3}$ were performed before, during, and after treatment. At the end of a month, three patients did not show any benefit. Seven patients showed subjective 